\title{
UNIVERSITY WEBSITE ACCESSIBILITY FOR TOTALLY BLIND USERS
}

\author{
Mohammed Saleh Hassouna, Noraidah Sahari \& Amirah Ismail \\ Faculty of Information Science and Technology \\ Universiti Kebangsaan Malaysia, Malaysia
}

mshassona@gmail.com; nsa@ukm.edu.my; amirahismail@.ukm.edu.my

\begin{abstract}
Researchers have discovered significant faults in the accessibility of university websites, especially for visually-impaired users. To determine the requirements for totally blind users, this study conducted a comprehensive literature review and accessibility evaluation on 15 Palestinian university websites. The determined factors were used in designing an accessible web page prototype. An online questionnaire was constructed to evaluate the accessibility of the prototype from the blind users' perspective. From the evaluation of 16 blind participants, it was found that the prototype was highly accessible (mean score 4.19). The regression analysis test was utilised to determine the relationship between the items and the main principles of accessibility. The results show that there are statistically significant differences between these items. In conclusion, the accessibility factors have been indirectly validated.
\end{abstract}

Keywords: Web accessibility, totally blind, WCAG 2.0, prototype evaluation.

\section{INTRODUCTION}

The World Wide Web (web) is one of the main sources of information. It is also a medium of communication. Hence, proper access to this network is necessary for all groups of society (Kurt, 2011; Wanniarachchi \& Jayathilake, 2012). Higher education institutions utilise the web for many purposes, and they provide many services through their websites such as learning resources, information and news. Therefore, university websites must be accessible to all users (Kurt, 2011) including people with or without impairments. The United Nations Convention on the Rights of Persons with Disabilities encourages 
information providers on the web to make their services accessible to persons with disabilities.

Accessibility is the degree of ability to access a product, device, service, or environment and the availability of these items to all individuals, in particular to those with disabilities or special needs. In the context of the web, how people with disabilities access, navigate, understand and react with the web is of major concern (Henry, 2005). The World Wide Web Consortium (W3C) provides the most important guidelines for web accessibility called the Web Content Accessibility Guidelines (WCAG). These guidelines could increase the accessibility level of web contents to make websites accessible to a wider range of disabled people including those with visual disabilities (Caldwell et al., 2008). Disabled individuals use assistive tools (AT) to access the web (Kurt, 2011). This tool varies according to the level of visual disability. For example, totally blind (TB) users usually use screen readers programmes, whereas partially blind (PB) users use screen magnifier programmes, and colour blind (CB) users use adaptive strategies by adapting to the display options of the operating system. The design of a web page should support compatibility with AT to enable handicapped people to access these pages (Abanumy et al., 2005).

Generally, most university homepages do not comply with the W3C guidelines (Harper \& DeWaters, 2008). The lack of access to information resources for visually disabled persons in higher education institutions could generate difficulties in their academic lives (Elaydi \& Shehada, 2007). Inaccessible web contents could affect a student's experience and learning, faculty and staff productivity, and overall timeliness and efficiency.

Universities have an obligation to offer accessible websites for all users. Based on the Palestinian Ministry of Higher Education Statistical Yearbook, the number of accredited higher education institutions is 53 . These institutions are distributed as follows: 14 traditional universities, one open university, 18 university colleges and 20 community colleges (MOHE, 2013). An early study by Hassouna and Sahari (2014) concluded that Palestinian university websites have significant accessibility weaknesses that may present many obstacles for disabled persons, especially for the visually handicapped. Thus, many users with visual impairment, especially totally blind users, are not able to access these sites effectively.

Worldwide, many evaluation studies have been conducted on the accessibility of public websites to identify accessibility problems (Elaydi \& Shehada, 2007). Nevertheless, accessibility evaluation studies conducted in this area 
focus on the government websites only. In addition, most studies tested the webpages' accessibility and they did not discover the factor that can improve the accessibility experience of the blind users.

To address this issue, accessibility factors for the totally blind were determined. Based on these factors, a prototype website was constructed to make it accessible for totally blind users. The study also evaluated the accessibility of university websites from the perspective of the visually-impaired users and developed an accessible model to assist developers in building accessible websites. However, this paper only discusses the evaluation aspect of web accessibility in Palestinian university websites for totally blind users.

\section{TOTALLY BLIND AND ACCESSIBILITY}

Visual disability is sight loss that may lead to blindness and will limit a person's visual ability and activities. Using the web is one of the daily activities affected by loss of vision. More importantly, the obvious tendency of websites to use visual content makes visually-impaired users one of the groups that could be impacted, thus these users must be distinguished when it comes to web accessibility (Harper et al., 2001; Babu et al., 2010; Al-Khalifa, 2012; Wanniarachchi \& Jayathilake, 2012). Moreover, the number of visually impaired people will continue to increase; making visual impairment one of the most challenging disabilities to address (Kim et al., 2013). Recently, the World Health Organisation (WHO) estimated that the number of visuallyimpaired people worldwide is 285 million; 39 million of them blind (WHO, 2014). In Palestine, a disabled-individual survey conducted in 2011 revealed that $2.7 \%$ of the Palestinian population had a disability where $0.6 \%$ of this number were visually disabled (PCBS \& MoSA, 2011).

The TB use their auditory senses to carry out web navigation tasks. Hence, the web page interface should be understandable, perceivable, navigable, and have the ability to be utilised successfully by visually-disabled users (Bakhsh $\&$ Mehmood, 2012). The TB generally use screen readers, speaking browsers, or braille readers (Brajnik, 2008).

Several studies have determined the potential factors that could make web pages accessible for people with visual disabilities. For instance, Lazar et al. (2007) conducted a study which reported the frustrated situations blind users experience when using the web and found that, on average, $30.4 \%$ of disabled users lose valuable time due to these difficulties. Some of the top reasons 
for these frustrating conditions are accessibility issues, namely no alternative text (ALT) for pictures and problems in page design that cause unclear screen reader feedback or misleading links.

Likewise, Baguma and Lubega (2008) handled a study to determine the requirements that could make the web more accessible to individuals with visual impairment. The study employed literature analysis and a case study to gather these requirements, and they observed that "graphical user interfaces, non-linear navigation, forms, tables, images, lack of keyboard support, nonstandard document formats, and acronyms and abbreviations hinder web accessibility for the blind" (Baguma \& Lubega, 2008, p. 392). In summary, they suggested some factors to make a web page more accessible. These included the provision of a text-only version of the website and the integration of the following considerations into the web design: provide ALT for visual elements; ensure the source code of the webpage provides meaningful content structure; provide skip navigation links; consider blind-user orientation during navigation; ensure that tables, frames, and forms are accessible; provide the ability to navigate the webpage by keyboard only; and code the web pages using a standard format.

In brief, visually-impaired people still face different obstacles when they use inaccessible websites. These barriers prevent them from carrying out their various tasks on the web without third party help. Moreover, AT will not work effectively if the web pages are not designed in an accessible way (Abanumy et al., 2005). People with disabilities use AT to access websites (Lazar et al., 2004; Kurt, 2011).

Several AT have been developed for visually-impaired users (Wanniarachchi $\&$ Jayathilake, 2012). The TB use screen readers to help them understand and browse web page content, which is often "confused by image maps, frames, Java Scripts, and other web design elements" (Slatin \& Rush, 2003, p. 534). Screen readers are computer applications utilised to recognise and describe the details of displayed web pages or computer screens by the TB users.

There is a close relationship between AT and web accessibility. Even with AT, website accessibility will still be an issue if the website is not designed properly. Kurt (2011) declared that websites must be designed properly under the mentioned guidelines and principles to support AT, so that they can work effectively and efficiently. Therefore, Slatin and Rush (2003) stated that webpages are only considered accessible web pages if they have adequate flexibility for use by various AT. 


\section{ACCESSIBILITY EVALUATION}

Abou-Zahra (2008) defined web accessibility evaluation as an assessment process to determine how disabled people use the web; the evaluation being a vast field combining various skills and disciplines. Accessibility evaluation can be done via three different evaluation techniques. One of them is the automatic method, while the other two are manual methods, all of which could be combined (Lang, 2003; Abou-Zahra, 2008; Koutsabasis et al., 2010; Freire, 2012). Figure 1 illustrates these methods. The first step involves the use of automatic evaluation tools; the second involves accessibility experts in reviewing websites according to the principles or guidelines; and the third involves real users attempting to perform certain tasks.

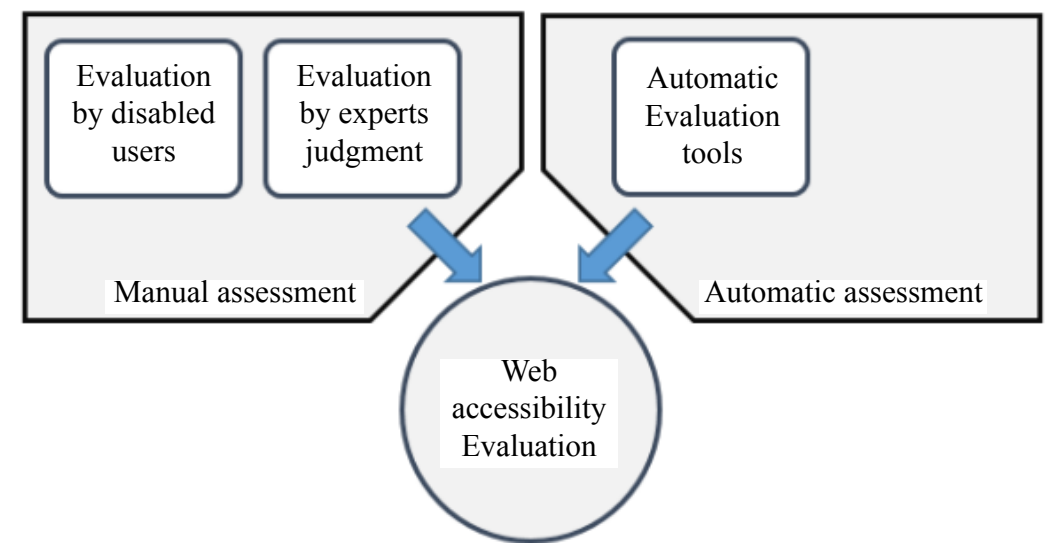

Figure 1. Web accessibility evaluation methods.

Automatic assessment tools have been broadly used in evaluating website accessibility (Lazar et al., 2010). Lazar et al. (2004) defined these tools as automated software designed to help web developers to discover the accessibility defects in their websites in advance before they are published. Moreover, these tools are mainly software or online services that assist in determining whether or not a site meets web accessibility guidelines (Koutsabasis et al., 2010). Several researchers have utilised these automated tools in their studies because they are free, easy to use, convenient, and abundant (Brophy \& Craven, 2007; Ringlaben et al., 2013). Overall, the automatic inspection tools produce reports that illustrate if each part in an interface adheres to or fails to adhere to guidelines (Lazar et al., 2010). According to Al-Khalifa (2011) these assessment tools can be categorised into two types. The first type is the general tools, which evaluate almost all 
guidelines, for example CynthiaSays, WAV, TAW, and AChecker. The second type of tools are the special is, which evaluate particular topics covered by web accessibility guidelines, for instance, the colour checker.

\section{METHODOLOGY}

This study was conducted in two phases, as shown in Figure 2. The two phases were utilised to reveal the accessibility factors for totally blind users. These factors were then validated by real blind users. The following sections explain the two phases in more detail.

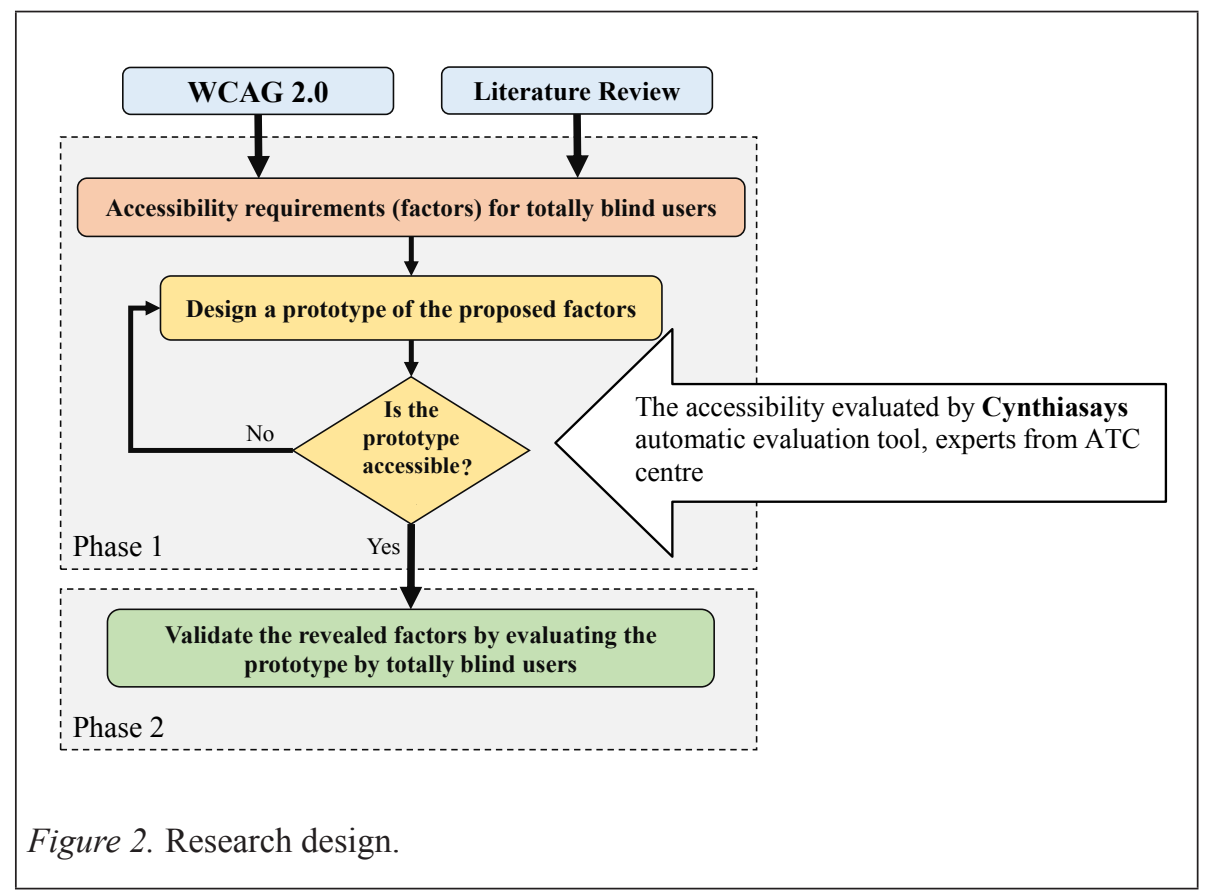

\section{Phase One of the Study}

Firstly, Phase 1 determined the accessibility factors for totally blind users from the literature in light of the WCAG 2.0 guidelines. Then, the study developed an accessible prototype based on these discovered factors. After that, the prototype was assessed using an iterative evaluation to ensure it complied with the determined factors. This was done using different accessibility evaluation methods to ensure it conformed to these factors. Thus, if the prototype failed in any of the proposed factors, it was returned to the design stage for problem repairs and for retesting. The study utilised the CynthiaSays automatic 
evaluation tool and manual assessment by expert judgment. Staff from the Assistive Technology Centre (ATC) at the Islamic University of Gaza (IUG) conducted this expert evaluation. The ATC staffs are familiar with the needs of visually-disabled people. They have real-life experience in this field and have a good knowledge of the problems faced by visually-disabled users when surfing the web. The feedback from the evaluation results were then used to refine the prototype to make sure it was accessible. Finally, the prototype was developed and was ready for validation by end-users in the second phase.

\section{Phase Two of the Study}

The second phase was the last stage. Its purpose was to validate the proposed factors. The validation process employes a quantitative method to validate the proposed factors. Thus, TB users were given the prototype for them to try out and provide feedback regarding its accessibility. The quantitative approach was utilised to evaluate each factor and to determine the relationship between these factors and the main principles of accessibility from the TB personal perspective. The TB persons were selected according to their type of visual impairment. They were required to perform browse-related tasks and other general tasks in the prototype. This phase was conducted from 20 December 2014 until 10 January 2015.

\section{Study Sampling}

The study focused on TB individuals. Recruiting persons with disabilities to conduct the study was one of the main challenges faced. Studies about disabilities often use small sample sizes (Lazar et al., 2010). The purposive cluster sampling was employed, which targets blind participants from the ATC centre at the Islamic University of Gaza (IUG) in Palestine. The ATC centre was established in 2000, and is considered the first university centre in Palestine concerned with visually-disabled persons, and aims to enable these people to fully participate in education (Elaydi \& Shehada, 2013). The latest statistics from ATC shows that the Islamic University of Gaza has 71 visuallyhandicapped persons in total; 41 of them are TB, and 30 are partially blind or colour blind. To measure the factors of accessibility from the perspective of TB persons, a questionnaire survey was conducted and 16 participants responded.

\section{Instrument Design}

The study utilised a questionnaire to measure the accessibility of the prototype. The questionnaire of this study began with demographic inquiries on gender and 
occupation. Then, the participants were asked about their experience in using their university website, and the assistive technology that they usually used for surfing the web. As shown in Table 1, the questionnaire factors and items were designed based on accessibility that has been retrieved from the literature review, and then translated into items. The next part of the questionnaire asked the participant about his/her experience with the prototype. There were seven accessibility factors related to TB users (TB1-TB7) and fourteen items (C1-C14) were constructed based on the WCAG2.0 criteria.

\section{Table 1}

\section{Questionnaire Design}

\begin{tabular}{|c|c|c|c|}
\hline \multirow{2}{*}{$\begin{array}{l}\text { Accessibility } \\
\text { principles }\end{array}$} & \multirow{2}{*}{$\begin{array}{l}\text { Proposed factors } \\
\text { (Related WCAG } 2.0 \text { guidelines/ } \\
\text { level) } \\
\text { TB }_{1} \text { : Provide alternative text } \\
\text { (ALT) for visual elements } \\
\text { and non-text elements, such } \\
\text { as images, graphics, objects, } \\
\text { graphic controls in forms, and } \\
\text { hotspots in image maps. (1.1 } \\
\text { Level A and 1.4.5 Level AA) }\end{array}$} & \multicolumn{2}{|c|}{ Questionnaire items } \\
\hline & & $\mathrm{C} 1$ & $\begin{array}{l}\text { The web page provides } \\
\text { alternative texts for images and } \\
\text { buttons. }\end{array}$ \\
\hline & \multirow{3}{*}{$\begin{array}{l}\mathrm{TB}_{2} \text { : Create an adaptable } \\
\text { webpage by enabling the } \\
\text { contents to be presented in } \\
\text { different ways (such as providing } \\
\text { simpler layouts) without losing } \\
\text { information or structure, and } \\
\text { programmatically preserve the } \\
\text { sequence of the content so it } \\
\text { makes sense. (1.3 Level A and } \\
3.2 \text { Level AA) }\end{array}$} & $\mathrm{C} 2$ & $\begin{array}{l}\text { Text headings and labels } \\
\text { of input fields give clear } \\
\text { understanding of their purpose. }\end{array}$ \\
\hline & & $\mathrm{C} 3$ & $\begin{array}{l}\text { The web page provides } \\
\text { summary information for } \\
\text { tables. }\end{array}$ \\
\hline & & $\mathrm{C} 14$ & $\begin{array}{l}\text { The webpage is presented in } \\
\text { different ways without loss of } \\
\text { information and structure. }\end{array}$ \\
\hline & $\begin{array}{l}\mathrm{TB}_{3} \text { : The page contains a link } \\
\text { that leads to a text-only page or a } \\
\text { low-graphics page. }(1.3 \text { Level } \mathrm{A})\end{array}$ & $\mathrm{C} 11$ & $\begin{array}{l}\text { The text-only page is a } \\
\text { comfortable way to surf the } \\
\text { webpage. }\end{array}$ \\
\hline \multirow[t]{3}{*}{ Understandable } & \multirow{3}{*}{$\begin{array}{l}\mathrm{TB}_{4} \text { : Provide assistance to the } \\
\text { user when using form elements } \\
\text { to prevent mistakes. (1.3 Level } \\
\text { A) }\end{array}$} & $\mathrm{C} 8$ & $\begin{array}{l}\text { The names of input fields are } \\
\text { properly described. }\end{array}$ \\
\hline & & C9 & $\begin{array}{l}\text { The web page identifies the } \\
\text { required field in the form. }\end{array}$ \\
\hline & & $\mathrm{C} 10$ & $\begin{array}{l}\text { In the forms, the web page } \\
\text { alerts users to identify errors. }\end{array}$ \\
\hline
\end{tabular}




\begin{tabular}{|c|c|c|c|}
\hline \multirow{2}{*}{$\begin{array}{l}\text { Accessibility } \\
\text { principles } \\
\text { Operable }\end{array}$} & \multirow{2}{*}{$\begin{array}{l}\text { Proposed factors } \\
\text { (Related WCAG } 2.0 \text { guidelines/ } \\
\text { level) } \\
\text { TB }_{5} \text { : All web page functionality } \\
\text { is available from the keyboard, } \\
\text { and can be navigated using the } \\
\text { keyboard only. ( } 2.1 \text { Level A) }\end{array}$} & \multicolumn{2}{|c|}{ Questionnaire items } \\
\hline & & $\mathrm{C} 4$ & $\begin{array}{l}\text { The web } \\
\text { page is accessible by keyboard } \\
\text { only. }\end{array}$ \\
\hline & \multirow{4}{*}{$\begin{array}{l}\mathrm{TB}_{6} \text { : The web page can be } \\
\text { navigated using (skip navigation } \\
\text { link, ability to bypass blocks, } \\
\text { provide meaningful page titles, } \\
\text { good focus order, prevent } \\
\text { confusing links, and use of } \\
\text { section headings). } \\
\text { ( } 2.4 \text { Level A and AA) }\end{array}$} & $\mathrm{C} 5$ & $\begin{array}{l}\text { The web page preserves the } \\
\text { visual sequence when the tab } \\
\text { key is used to navigate. }\end{array}$ \\
\hline & & C6 & $\begin{array}{l}\text { The web page provides } \\
\text { different ways to navigate and } \\
\text { browse its contents. }\end{array}$ \\
\hline & & $\mathrm{C} 7$ & $\begin{array}{l}\text { The web page title is } \\
\text { meaningful. }\end{array}$ \\
\hline & & $\mathrm{C} 12$ & $\begin{array}{l}\text { The skip navigation links allow } \\
\text { for ease of site navigation. }\end{array}$ \\
\hline \multirow[t]{2}{*}{ Interactive } & $\begin{array}{l}\mathrm{TB}_{7} \text { : Maximise compatibility } \\
\text { with current and future user } \\
\text { agents, including assistive } \\
\text { technologies. }\end{array}$ & $\mathrm{C} 13$ & $\begin{array}{l}\text { The screen reader programme is } \\
\text { compatible with the webpage. }\end{array}$ \\
\hline & $\begin{array}{l}\text { ( } 4.1 \text { Level A and } 3.1 \text { Level A and } \\
\text { AA) }\end{array}$ & & \\
\hline
\end{tabular}

Although the traditional way to conduct a survey is to use paper-based questionnaires, people with visual disability prefer to use a web-based survey instead of the paper-based survey (Lazar et al., 2010). Web-based surveys can facilitate immediate input validation, automatically skip items that are irrelevant to some participants, provide faster response rate, and automatically transfer answers into a datasheet for analysis (Ritter \& Sue, 2007). Therefore, the study employed the online questionnaire approach using Google Drive as the tool to design the questionnaire. In addition, the study took into consideration accessibility issues for visually-disabled persons when the online questionnaire tool was selected. Thus, the accessibility of the questionnaire was first manually tested using the NVDA screen reader programme before being distributed.

The questionnaire adopted a 5-point Likert scale for each question. The five scale answers were based on the following: 1- strongly disagree, 2- disagree, 3- somewhat agree, 4- agree, 5- strongly agree. In brief, the questionnaire was designed and refined via five major steps in which amendments and updates were performed after each step. First, the 
questionnaire was initally designed by translating the factors into items. Second, three experts from related areas validated the questionnaire. Third, the questionnaire was translated into the Arabic language after which it underwent the proofreading process. Fourth, the questionnaire was converted into the web-based format using Google Drive. Lastly, the accessibility of the web-based survey tool were tested and administered to the intended sample.

\section{Data Analysis}

Upon completing the evaluation, data analysis was done using the SPSS 21 software. The study employed statistical analysis and descriptive analysis methods to test the reliability of the questionnaire. Linear regression analysis (simple and multiple) was utilised to analyse the relationship between the questionnaire items and the dependent variables, which were the main accessibility principles, after the normality assumption had been satisfied.

\section{FINDINGS}

The results of the study consist of two phases. The first phase is the presentation of the results of the prototype design and the second phase explains the validation result of the model.

\section{Phase One Results}

The outcome of this phase was the prototype design used to validate the proposed model. The prototype was developed based on the factors of the proposed model. The layout and structure of the prototype were similar to the general layout and structure of the university website. To comply with the proposed model's factors, the prototype page provided the correct language declaration to make the webpage more compatible with assistive technologies. The prototype provided adequate ALT text for images-presenting content or images-presenting function such as image buttons. Decorative images were tagged with null ALT (alt="'). The prototype also included skip navigation links. Most university websites have a long list of links. Links to a friendly text-only page with a simpler layout for screen reader users would benefit TB users during their navigation in which they would be able to bypass these links and arrive directly at the main content.

All prototype functionalities were developed to be accessible by keyboard only, especially the main menu. Semantic markup was used to structure its 
text contents correctly by including headings (such as $\mathrm{H} 1, \mathrm{H} 2, \mathrm{H} 3$ ). This technique resulted in a meaningful structure, correct navigation order, and increased the adaptation ability of the webpage. The layout of the prototype webpage utilised the ARIA landmark to identify web page sections. This would assist screen reader users to orient themselves and facilitate the navigation of various regions of the web page. In addition, a 'Contact Us' form in the prototype provided adequate labels for the input fields, indicating the required fields, and would help users to identify any input errors. The form moved the cursor automatically to problematic fields. Data tables in the prototype would have a summary abstract about the tables and their contents, where the table content was identified from its headers, columns, and rows. This technique would make the tables more accessible particularly for screen reader users.

After the prototype was developed, it was then evaluated by different evaluation methods to guarantee its conformance to the proposed model's factors. The results from the CynthiaSays automatic evaluation tool showed that the prototype had an intermediate level of accessibility, compliance to Level AA under the WCAG 2.0 guidelines. The manual evaluation, which was done by experts from the ATC centre, had also yielded good feedback on the accessibility of the prototype. Experts could not reveal the problems that would have been faced by visually-disabled users when surfing the web. After this evaluation, the prototype was ready to be utilised in the proposed model validation in Phase Two.

\section{Phase Two Results}

The results for this phase stemmed from the validation of the proposed model. The validation was done via the conducting of a survey on the developed prototype for an accessible university web page. The survey was conducted at the ATC centre of the Islamic University of Gaza (IUG), Palestine. The questionnaire was distributed to all the blind users who studies at the ATC centre. A total of $16 \mathrm{~TB}$ users (44\% males and $56 \%$ females) responded to the questionnaire. The Cronbach's alpha reliability test showed that the TB subscale consisted of 18 items $(\alpha=0.73)$ and were reliable. The questionnaire results were tabulated and analysed using SPSS and are presented in the following sections.

shows the distribution of gender in the blind user participants. The questionnaire results were tabulated and analysed using SPSS and are presented in the following sections. 
Table 2

Gender of Surveyed Users

\begin{tabular}{lcc}
\hline \multicolumn{1}{c}{ Gender } & Number & Percentage \\
\hline Male & 7 & $44 \%$ \\
Female & 9 & $56 \%$ \\
Total & $\mathbf{1 6}$ & $\mathbf{1 0 0 \%}$ \\
\hline
\end{tabular}

\section{Accessibility Score of the Prototype}

This section presents the findings of the descriptive analysis of the survey. Due to the use of a five-point Likert scale in the questionnaire items, the researchers divided the mean score into three levels; low (0 to 1.67), medium (1.68 to 3.33), and high (3.34 to 5). Table 3 shows the mean range of prototype accessibility from the TB users' perspective. Generally, the evaluation findings of these users proved that the prototype was accessible. They also highly agreed with its accessibility. The mean of the 14 items ranged from 3.56 to 4.56. Therefore, all of these items' results were categorised as high level. The minimum mean was 3.56 for the item, "The name of input fields describes them properly", whilst the highest mean is 4.56 for item, "The screen reader programme is compatible with the web page".

Table 3

Results of Questionnaire Items

\begin{tabular}{|c|c|c|}
\hline No. & Item & Mean \\
\hline & Perceivability & \\
\hline $\mathrm{C} 1$ & The web page provides alternative text for images and buttons. & 4.00 \\
\hline $\mathrm{C} 2$ & $\begin{array}{l}\text { Text headings and labels of input fields give a clear understanding } \\
\text { of their purpose. }\end{array}$ & 4.13 \\
\hline $\mathrm{C} 3$ & The web page provides summary information about tables. & 4.31 \\
\hline $\mathrm{C} 11$ & The text-only page is a comfortable way to surf the web page. & 4.25 \\
\hline \multirow[t]{3}{*}{$\mathrm{C} 14$} & $\begin{array}{l}\text { The web page is presented in different ways without loss in } \\
\text { information and structure (e.g. simpler layout like Text-only page). }\end{array}$ & 4.44 \\
\hline & Perceivability Mean Score & 4.23 \\
\hline & Understandability & \\
\hline $\mathrm{C} 8$ & The names of input fields are described properly. & 3.56 \\
\hline $\mathrm{C} 9$ & The web page identifies the required field in the forms. & 3.81 \\
\hline
\end{tabular}




\begin{tabular}{|c|c|c|}
\hline No. & Item & Mean \\
\hline \multirow[t]{3}{*}{$\mathrm{C} 10$} & In the forms, the web page alerts users to identify errors. & 4.19 \\
\hline & Understandability Mean Score & 3.85 \\
\hline & Operability & \\
\hline $\mathrm{C} 4$ & The web page is accessible by keyboard only. & 4.31 \\
\hline C5 & $\begin{array}{l}\text { The web page preserves the visual sequence when the tab key is } \\
\text { used to navigate. }\end{array}$ & 4.13 \\
\hline C6 & $\begin{array}{l}\text { The web page provides different ways to navigate and to browse } \\
\text { its contents (such as headings, landmark, and skip navigation } \\
\text { links) }\end{array}$ & 4.13 \\
\hline $\mathrm{C} 7$ & The web page title is meaningful. & 4.31 \\
\hline \multirow[t]{3}{*}{$\mathrm{C} 12$} & The skip navigation links allows for ease of site navigation. & 3.81 \\
\hline & Operability Mean Score & 4.14 \\
\hline & Interactivity & \\
\hline \multirow[t]{3}{*}{$\mathrm{C} 13$} & The screen reader programme is compatible with the web page. & 4.56 \\
\hline & Interactivity Mean Score & 4.56 \\
\hline & Accessibility Mean Score for TB & 4.19 \\
\hline
\end{tabular}

Overall, the mean score for the questionnaire items was 4.19 , placing it at a high level. The mean scores reported for Perceivability, Understandability, Operability, and Interactivity were $4.23,3.85,4.14$, and 4.56 , respectively.

\section{Model Validation}

Table 4 shows the summary of the Linear regression analysis for this study. The perceivability of the model was significant $(\mathrm{p}<0.05)$, and the adjusted determination factor (R2), equal to 0.94 , indicated that about $94 \%$ of the TB users perceivability was predicted and determined by $\mathrm{C} 1, \mathrm{C} 2, \mathrm{C} 3, \mathrm{C} 11$, and C14. The understandability of the model was significant $(\mathrm{p}<0.05)$, and the adjusted determination factor (R2), equal to 0.94 , indicated that about $94 \%$ of the TB users' understandability was predicted and determined by $\mathrm{C} 8, \mathrm{C} 9$, and $\mathrm{C} 10$. The operability of the model was significant $(\mathrm{p}<0.05)$, and the adjusted determination factor (R2), equal to 0.95 , indicated that about $95 \%$ of the TB operability was predicted and determined by $\mathrm{C} 4, \mathrm{C} 5, \mathrm{C} 6, \mathrm{C} 7$, and $\mathrm{C} 12$. The regression result of the interactivity factor was significant $(\mathrm{p}<0.05)$, and the determination factor (R2), equal to 0.69 , indicated that about $69 \%$ of the TB users' interactivity was predicted and determined by C13.

According to the results, all factors of the proposed model i.e. Perceivability, Understandability, Operability, and Interactivity were statistically significant. The result and validations process thus formed the final Accessibility Model for Totally Blind users, as shown in Figure 3. 
Table 4

Summary of the Linear Regression Analysis

\begin{tabular}{|c|c|c|c|}
\hline $\begin{array}{l}\text { Accessibility } \\
\text { principles }\end{array}$ & Regression equation & Sig & $\begin{array}{c}\mathrm{R}^{2} \\
\text { adjusted }\end{array}$ \\
\hline Perceivable & $\begin{array}{l}\text { TB perceivability }=-0.93+(0.31 * \mathrm{C} 1)+ \\
(0.36 * \mathrm{C} 2)+(0.33 * \mathrm{C} 3)+(0.32 * \mathrm{C} 11)+ \\
(0.31 * \mathrm{C} 14)\end{array}$ & $<0.001$ & 0.94 \\
\hline Understandable & $\begin{array}{l}\text { TB understandability }=-1.25+(0.82 * \mathrm{C} 10) \\
+(0.51 * \mathrm{C} 9)+(0.43 * \mathrm{C} 8)\end{array}$ & $<0.001$ & 0.94 \\
\hline Operable & $\begin{array}{l}\text { TB operability }=-0.54+\left(0.39^{*} \mathrm{C} 4\right)+ \\
\left(0.38^{*} \mathrm{C} 6\right)+(0.43 * \mathrm{C} 5)+\left(0.26^{*} \mathrm{C} 7\right)+ \\
(0.25 * \mathrm{C} 12) .\end{array}$ & $<0.001$ & 0.95 \\
\hline Interactive & $\mathrm{TB}$ interactivity $=0.28+(0.83 * \mathrm{C} 13)$ & $<0.001$ & $\mathrm{R}^{2}=0.69$ \\
\hline
\end{tabular}

Totally Blind (TB) Accessibility Factors

Assistive Technology used: Screen reader, refreshable braille display, or voice browser.

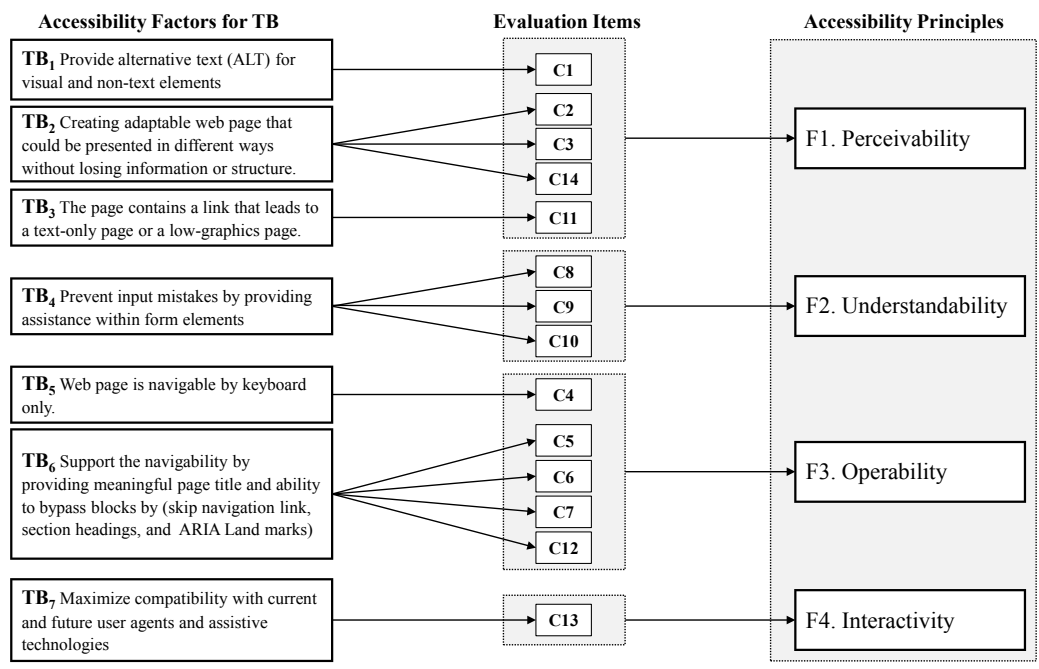

Figure 3. Accessibility model for totally blind users.

\section{CONCLUSION AND FUTURE WORKS}

A comprehensive literature review was conducted regarding web accessibility, international guidelines, evaluation methods, visual disabilities, and factors that the developers should take into account when designing websites for visually- 
disabled users. This paper highlighted the significant accessibility problems that could hinder TB users. The study was divided into two phases. The first phase revealed the proposed accessibility factors for TB users. These factors were identified from WCAG guidelines. The design of the prototype simulated the design of most Palestinian university web pages. The researchers decided to develop a high fidelity prototype to increase interactivity and to facilitate the evaluation by visually-disabled users. The study developed the prototype by utilising the Throwaway prototyping method, which was included in the framework of this study. The prototype compliance to the proposed model factors was tested before evaluation it by end users.

The second phase was conducted to indirectly validate the proposed model by evaluating the prototype that was developed. The evaluation of the prototype was carried out at the ATC centre of the Islamic University of Gaza, Palestine. The researchers constructed an online questionnaire with a 5-point Likert scale based on the identified accessibility factors. In addition, the accessibility of the questionnaire was tested to make sure it was suitable for totally blind users. The findings collected from 16 participants showed that the prototype was highly accessible for totally blind users. The regression analysis test was utilised to determine the relationship between the items of the questionnaire and the main principles of accessibility. The results show that there are statistically significant differences between these items. In conclusion, the accessibility model is therefore validated. The limitation of this study is that not all disabilities were included. In addition, the sample size was quite small. Further research could be conducted in many areas involving accessibility of websites. For instance, the study framework could be applied to other groups with different disabilities.

\section{ACKNOWLEDGMENTS}

This work was supported by Universiti Kebangsaan Malaysia, the Multimedia Software and Usability Research Group and ERGS/1/2013/ICT05/UKM/02/3 research grant.

\section{REFERENCES}

Abanumy, A., Al-Badi, A., \& Mayhew, P. (2005). e-Government website accessibility: In-depth evaluation of Saudi Arabia and Oman. The Electronic Journal of e-Government, 3(3), 99-106. 
Abou-Zahra, S. (2008). Web accessibility evaluation. Web accessibility. S. Harper and Y. Yesilada, Springer London, 79-106.

Al-Khalifa, H. S. (2012). The accessibility of Saudi Arabia government web sites: An exploratory study. Universal Access in the Information Society, 11(2), 201-210.

Babu, R., Singh, R., \& Ganesh, J. (2010). Understanding blind users' web accessibility and usability problems. AIS Transactions on HumanComputer Interaction, 2(3), 73-94.

Baguma, R., \& Lubega, J. (2008). Web design requirements for improved web accessibility for the blind. Hybrid Learning and Education. In J. Fong, R. Kwan., \& F. Wang (Eds.), Human-Computer Interaaction and Usabilty Engineering of the Austrian Computer Society Proceedings, 5169: Springer Berlin Heidelberg, 392-403.

Bakhsh, M., \& Mehmood. (2012). A. web accessibility for disabled: A case study of government websites in Pakistan. Frontiers of Information Technology (FIT), 2012 10th International Conference on IEEE, 342-347.

Brajnik, G. (2008). Beyond conformance: The role of accessibility evaluation methods. Web Information Systems Engineering-WISE 2008 Workshops, Springer, 63-80.

Caldwell, B., Cooper, M., Reid, L. G., \& Vanderheiden, G. (2008). Web content accessibility guidelines (wcag) 2.0. W3C Recommendation. World Wide Web Consortium (W3C) 11.

Elaydi, H., \& Shehada, H. (2007). A source of inspiration: ATC for visually impaired students at the Islamic University of Gaza. ICTA 7, 12-14.

Elaydi, H. A., \& Shehada, H. (2013). Effective factors in successful use of assistive technology at Palestinian universities: Islamic University of Gaza as Case Study. International Journal of Engineering Sciences \& Research Technology, 2(4),660-664.

Freire, A. P. (2012). Disabled people and the web: User-based measurement of accessibility. Computer Science.University of York.

Harper, K. A., \& DeWaters, J. (2008). A quest for website accessibility in higher education institutions. The Internet and Higher Education, $11(3), 160-164$. 
Harper, S., Goble, C. A., \& Stevens, R. (2001). Web mobility guidelines for visually-impaired surfers. Journal of Research and Practice in Information Technology, 33(1), 30-41.

Hassouna, M. S., \& Sahari, N. B. (2014). Palestinian universities' website accessibility: An initial view. International Conference on Postgraduate Research 2014 (ICPR 2014), Kuala Lumpur, Malaysia, 327 - 335.

Henry, S. (2005). Introduction to web accessibility. Retrieved from http:// www.w3.org/WAI/intro/accessibility.php.

Kim, H. N., Smith-Jackson, T. L., \& Kleiner, B. M. (2013). Accessible haptic user interface design approach for users with visual impairments. Universal Access in the Information Society, 1-23.

Koutsabasis, P., Vlachogiannis, E., \& Darzentas, J. S. (2010). Beyond specifications: Towards a practical methodology for evaluating web accessibility. Journal of Usability Studies, 5(4),157-171.

Kurt, S. (2011). The accessibility of university websites: The case of Turkish universities. Universal Access in the Information Society, 10 (1): 101-110.

Lang, T. (2003). Comparing website accessibility evaluation methods and learnings from usability evaluation methods. Peak Usability.

Lazar, J., Allen, A., Kleinman, J., \& Malarkey, C. (2007). What frustrates screen reader users on the web: A study of 100 blind users. International Journal of Human-Computer Interaction, 22(3), 247-269.

Lazar, J., Dudley-Sponaugle, A., \& Greenidge, K.-D. (2004). Improving web accessibility: A study of webmaster perceptions. Computers in Human Behavior, 20(2), 269-288.

Lazar, J., Feng, J. H., \& Hochheiser, H. (2010). Research methods in humancomputer interaction: John Wiley \& Sons.

PCBS, P. C. B. O. S., \& MoSA, M. o. S. A. (2011). Disabled individuals survey, main findings report.

Ritter, L. A., \& Sue, V. M. 2007. Introduction to using online surveys. New Directions for Evaluation, (115), 5-14. 
Slatin, J. M., \& Rush, S. (2003). Maximum accessibility: Making your web site more usable for everyone: Addison-Wesley Professional.

Wanniarachchi, H., \& Jayathilake, D. (2012). A framework for building websites that are friendly to visually impaired. Advances in ICT for Emerging Regions (ICTer), 2012 International Conference on IEEE, 103-110.

WHO, W. H. O. (2014). Visual impairment and blindness. Retrieved from http://www.who.int/mediacentre/factsheets/fs282. 